\section{P6.070 PREVALENCE OF DEPRESSIVE SYMPTOMS IN PEOPLE LIVING WITH HIV/AIDS IN THE BRAZILIAN CITY}

doi:10.1136/sextrans-2013-051184.1223

C C Castrighini, R K Reis, L A S Neves, F G Morales, E Gir. Nursing School of Ribeirão Preto, University of São Paulo, Ribeirão Preto, Brazil

Prevalence of depressive symptoms in people living with HIV/aids in the Brazilian city

Carolina de Castro Castrighini, Renata Karina Reis, Lis Aparecida de Souza Neves, Fabíola Garcia Morales, Elucir Gir

Background Several challenges are imposed in the course of HIV/ aids, including the mental health care. This study aims to assess depressive symptoms of people living with HIV/aids and correlate with sociodemographics and clinical factors.

Methods This is a cross-sectional study, conducted in two specialised ambulatory care to individuals with HIV/AIDS located in a city in the interior. We evaluated sociodemographic and clinical variables. For evaluation of depressive symptoms was used Beck Depression Inventory.

Results The study included 331 people living with HIV/AIDS, and $167(50.5 \%)$ were male. The mean age was 39 years. It was found that most 195 (58.9\%) of subjects had up to 8 years of study. Refers clinical characteristics showed that $156(47.1 \%)$ subjects were classified as AIDS, 267 (80.7\%) had CD4 above 200 cells $/ \mathrm{mm}^{3}$ and 176 $(53.2 \%)$ had no others comorbidities. The prevalence of depressive symptoms was $29.6 \%$ (BDI > 16), with $6.6 \%$ classified with mild symptoms (BDI 16-20), 12.4\% moderate (20 to 29 ) and 10.6\% (BDI 30-63) with severe symptoms.

Conclusions Data analysis showed that most participants were young, males, with low education which corroborates with the profile found in this population. Services and health professionals, especially nurses, should be able to provide comprehensive care to individuals with HIV/aids, considering clinical and emotional aspects.

\section{P6.071 PROJECTS FOR STRENGTHEN CIVIL SOCIETY'S ACTIONS RELATED TO THE STD/HIV/AIDS AND VIRAL HEPATITIS EPIDEMIC}

doi:10.1136/sextrans-2013-051184.1224

N Correia, N Lima, L Seara, M Colombo, D Oliveira, G Casimiro, B Barbosa. Ministério da Saúde - Departamento de DST, Aids e Hepatites Virais, Brasília, Brazil

Background Since 1999, the Brazilian STD, AIDS and Viral Hepatitis Program has funded Civil Society projects selected through public calls for proposals for strengthening health promotion campaigns. The priority populations are people living with HIV/AIDS (PLWHA), carriers of viral hepatitis, and segments of the population at greater risk of contracting STDs.

Methods Strengthening of campaigns and field interventions for populations in circumstances of great vulnerability to STDs, HIV/ AIDS and viral hepatitis, taking into consideration the epidemiological relevance of each region;

Expansion of systemic educational interventions that contribute to broaden and improve diagnosis, prevention, health promotion, and human rights relative to STDs, HIV/AIDS and viral hepatitis;

Campaigns to reduce the harm caused by alcohol and drugs, with a focus on prevention, health promotion, and STD, HIV/AIDS and viral hepatitis diagnosis;

Participation by PLWHA and/or carriers of viral hepatitis in the formulation of policies, thus contributing to the improvement of the organisation of services, community mobilisation, and societal control;

Actions to reduce stigma and discrimination related to living with HIV/AIDS and viral hepatitis, and promotion of the usage of prevention inputs.
Results From 1999 to 2012, 6,419 projects were financed, totaling $\mathrm{R} \$ 248,764,148.54$ (approximately U\$ 124 million).

The results of the projects contribute to health promotion campaigns by strengthening and/or expanding actions for: the prevention of STD/HIV/AIDS, encouraging STD/HIV/AIDS diagnosis, prevention, societal control, legislation, and implementation of integrated strategies in public services.

Conclusion Governmental budget is an important key to strength and support the civil society organisations in their participation on development and implementation of healthcare promotion policies.

\section{P6.072 DIFFERENCES AMONG CANADIAN FAMILY PRACTITIONERS BY YEARS OF PRACTISE IN UPTAKE OF SEXUALLY TRANSMITTED AND BLOOD-BORNE INFECTIONS (STBBIS) CLINICAL RECOMMENDATIONS}

doi:10.1136/sextrans-2013-051184.1225

'J Seto, ${ }^{1} 0$ Kapral, 'T Wong, 'M Gale-Rowe, 'A Demers, ' $\mathrm{J}$ Dodds, ${ }^{2} \mathrm{~W}$ Fisher, ${ }^{3} \mathrm{M}$ Steben, ${ }^{4} \mathrm{R}$ Read. 'Public Health Agency of Canada, Ottawa, ON, Canada; ${ }^{2}$ University of Western Ontario, London, ON, Canada; 'Institut national de santé publique du Québec, Montréal, OC, Canada; ${ }^{4}$ University of Calgary, Calgary, AB, Canada

Background Clinical guidelines play a critical role in the prevention and control of sexually transmitted and blood-borne infections (STBBIs). Little is known in Canada as to the uptake of clinical recommendations and the comfort-level of family practitioners performing STBBI-related clinical tasks.

Methods To evaluate the prevention and control of STBBIs by family practitioners, information was elicited from a convenience sample $(\mathrm{N}=207)$ of family practitioners at a national Canadian family medicine forum in Toronto between November 15 and 17, 2012 using two methods: audience response systems (during a symposium) and a self-administered questionnaire at an exhibition booth. Analysis was stratified by years of practise to identify any differences in STI risk assessments, treatment of gonorrhoea and offering of HIV testing. The Fisher's exact and chi-square tests were used to determine statistical significance.

Results Approximately $26.3 \%$ of early-career-practitioners (<5-yrs) and $15.9 \%$ mid-to-late-career-practitioners $(\geq 5 \mathrm{yrs})$ reported doing an STI risk assessment during a health exam $(p=0.08)$. Overall, in their treatment of choice for gonorrhoea, most selected cefixime $(52.2 \%$; ceftriaxone: $19.5 \%$; and azithromycin: $15.1 \%)$. More early-career-practitioners selected cefixime than midto-late-career-practitioners $(51.5 \% ; 48.4 \%$, respectively; $\mathrm{p}=0.2)$. In the past year, a greater proportion of mid-to-late-career $(54.3 \%)$ than early-career-practitioners $(40.8 \%$; $p=0.05)$ reported that they offered HIV testing to $10 \%$-or-less of their patients. A comparable percentage of early-career $(25.5 \%)$ and late-career $(20.3 \%)$ practitioners said they offered HIV testing to $50 \%$-or-more of their patients $(p=0.3)$. After learning about upcoming new HIV screening and testing recommendations, $50.2 \%$ of early-career compared to $35.7 \%$ of mid-to-late career practitioners said they would offer HIV testing more often $(p=0.07)$. More early-career-practitioners $(48.5 \%)$ were willing to offer an HIV test while testing for other STIs compared to mid-to-late-career-practitioners $(41.7 \%$; $p=0.3)$.

Conclusions Results indicate a need to improve uptake of STI and HIV clinical recommendations among all practitioners, but particularly among mid-to-late-career practitioners.

\section{P6.073 USE OF EVIDENCE-BASED RESULTS IN GOVERNMENTAL DECISION-MAKING PROCESSES IN THE BRAZILIAN MINISTRY OF HEALTH}

doi:10.1136/sextrans-2013-051184.1226

F M A Souza, S P Giozza. Departamento de DST/AIDS/Hepatites Virais/Ministério Da Saúde, Brasília, Brazil 
Background Brazil invests more in scientific research than any other Latin American country. Its Ministry of Health is a source of funding for research, along with other development agencies, and its Department of STDs, HIV/AIDS and Viral Hepatitis is one of the agencies that most strongly supports and promotes research in the field of STDs/HIV/AIDS in Brazil. However, it remained to be seen whether or not effective use is being made of scientific evidence during public health policy formulation and if it is being used to validate the government's decision-making process. The purpose of this study was to assess the use of scientific evidence produced by projects funded by the Department.

Methods An exploratory study was carried out that surveyed former directors of the Department. Questions were asked concerning the Department's institutional mission, support for research and technological development, use of the results of research projects, and use of these projects' scientific evidence during public health policy formulation.

Results Analysis of the data showed that the Department has promoted and encouraged research studies and technological development, in partnership with centres for excellence in research, institutes of higher education, and national and international development agencies, and has funded 220 projects since 2004 , resulting in 1,198 scientific publications. Despite these contributions to advances in scientific knowledge, the present study showed that incorporation of scientific evidence was limited to research the Department had specifically requested, such as economic and strategic analyses and studies on operational programmes.

Conclusion Strategies for integrating science-based evidence with its practical application should be identified. Science-based evidence should be disseminated, promoted and incorporated into the process of developing public health policies, strategies, and practises.

\section{P6.074 TAILORING CLINICAL KNOWLEDGE PRODUCTS FOR GUIDANCE ON ADDRESSING SEXUALLY TRANSMITTED INFECTIONS AND BLOOD-BORNE INFECTION (STBBIS) TO MEET THE DIFFERENT NEEDS OF FAMILY MEDICINE PRACTITIONERS IN CANADA}

doi:10.1136/sextrans-2013-051184.1227

'J Seto, ${ }^{10}$ Kapral, ${ }^{1} \mathrm{~T}$ Wong, ${ }^{1} \mathrm{M}$ Gale-Rowe, ${ }^{1} \mathrm{~A}$ Demers, ${ }^{1} \mathrm{~J}$ Dodds, ${ }^{2} \mathrm{~W}$ Fisher, ${ }^{3} \mathrm{R}$ Read, ${ }^{4} \mathrm{M}$ Steben. 'Public Health Agency of Canada, Ottawa, ON, Canada; ${ }^{2}$ University of Western Ontario, London, ON, Canada; ${ }^{3}$ University of Calgary, Calgary, AB, Canada; 4/nstitut national de santé publique du Québec, Montréal, OC, Canada

Background Moving clinical guidelines into practise requires the development of clinical knowledge products to aid family practitioners. A variety of product types and formats may need to be used to suit different needs by career-stage.

Methods To evaluate the sexually transmitted and blood-borne infections (STBBI) knowledge product needs of practitioners, information was elicited from a convenience sample $(\mathrm{N}=207)$ of family medicine practitioners at a national Canadian family medicine forum in Toronto between November 15 and 17, 2013. Analysis was stratified by years of practise to identify ways to reach different generations of practitioners concerning STI and HIV clinical recommendations. The Fishers exact and chi-square test was used to determine statistical significance. Data was collected on preferences on clinical aids; methods used to update clinical knowledge; and preferred formats of accessing STI guidelines.

Results All practitioners expressed preferences for concise clinical aids such as algorithms (64.2\%) and abbreviated pocket guides $(35.3 \%)$, in addition to prompts on electronic medical records $(32.9 \%)$. On-line training and education were preferred by earlycareer practitioners ( $<5$-yrs: $53.3 \%)$, compared to their mid-to-late career $(\geq 5 y r s)$ counterparts $(26.1 \% ; p=0.004)$. More mid-to-late- career practitioners preferred classroom style workshops $(73.9 \%)$ than their early-career counterparts $(46.7 \% ; p=0.004)$. There were differences $(p=0.04)$ by years of practise concerning guideline format preferences. Early-career practitioners preferred mobile applications (38.5\%) compared to hard-copy materials (17.6\%). Mid-to-late-career practitioners appeared to prefer hard-copy materials $(31.2 \%)$ in addition to mobile applications (37.7\%).

Conclusions These findings demonstrate generational differences in preferred formats and methods of accessing STI and HIV clinical information; public health programmes may wish to deliver information using different approaches to reach different practitioners.

\section{P6.075 ATTEND TO THE "SMALL P" POLICY ISSUES: STATE POLICY ISSUES PREVENTING EFFECTIVE CERVICAL CANCER EFFORTS}

doi:10.1136/sextrans-2013-051184.1228

'B E Meyerson, 'C A Lawrence, ${ }^{2} \mathrm{~J}$ S Smith. 'Indiana University School of Public Health-Bloomington, Bloomington, IN, United States; ${ }^{2}$ UNC Gillings School of Global Public Health, Chapel Hill, NC, United States

Background We know little about policy issues at state level that impede cervical cancer efforts in the US. This study identifies and explores state policy issues in cervical cancer to inform future policy and programme strategies.

Methods Sixty minute key informant interviews were conducted with 15 professionals working in and around cervical cancer: federal and state government breast and cervical cancer programmes; women's health and cancer control; national advocacy organisations engaged in sexual health and cancer; legislative affairs; researchers working in cervical cancer intervention and evaluation; state coalitions engaged in cervical cancer efforts; and partners from industry working on diagnostics, therapeutics or vaccines.

Results State policy issues included health system complexity; lack of state level cervical cancer programme and policy coordination, and socio-organisational culture issues. System complexity was fueled by disparate and uncoordinated financing, controlled by different state programmes/agencies. A paucity of state level coordination exacerbated by a lack of cervical cancer inter-agency/programme influence prevented comprehensive, streamlined systems of care. Despite recent efforts to coordinate statewide cancer planning, cervical cancer issues and actors were not active in state priority setting. Socio-organisational cultural issues prevented normalisation of HPV vaccine for boys and girls, as well as programme and practitioner adoption of recent screening recommendations focused on identifying and monitoring persistent HPV.

Conclusions Critical state policy issues are not 'big p' issues or laws, but 'small p' issues of implementation and unintended systems outcomes of policy. Cross-agency, statewide planning could streamline systems for comprehensive and coordinated funding and policy. Critical need to address state leadership vacuum for cervical cancer efforts. Increasing the policy acumen and skill set of cervical cancer related programmes and coalitions could facilitate change navigation. Success at this 'small p' policy level will help to make big strides toward removing structural barriers to cervical cancer efforts in the U.S.

\section{P6.076 OUALITY OF LIFE AND ITS RELATIONSHIP WITH THE CLINICAL ASPECTS PEOPLE LIVING WITH HIV/AIDS IN BRAZIL}

doi:10.1136/sextrans-2013-051184.1229

${ }^{1}$ R K Reis, ${ }^{2} \mathrm{E}$ Gir, ${ }^{3} \mathrm{M}$ T G Galvão. 'Nursing School of Ribeirão Preto, University of São Paulo, Ribeirão Preto-São Paulo, Brazil; ${ }^{2}$ Nursing School of Ribeirão Preto, University of São Paulo, Ribeirão Preto, Brazil; ${ }^{3}$ Professor of Nursing Course at Federal University of Ceará, Fortaleza, Brazil 